\title{
Die and Die Materials - An Overview
}

\section{Sunny Sharma ${ }^{1}$, Lucky Jindal ${ }^{2 *}$, Abhishek Kumar ${ }^{3}$, Kumar Gaurav ${ }^{4}$, Rudhra Munshi ${ }^{5}$, Anukriti ${ }^{6}$}

${ }^{1}$ Senior Lecturer, Department of Prosthodontics and Implantology, Himachal Institute of Dental Sciences, Paonta Sahib, Himachal Pradesh, India

${ }^{2}$ Senior Lecturer, Department of Paedodontics and Preventive Dentistry, JCD Dental College, Sirsa, Haryana, India

${ }^{3}$ MDS, Paedodontics and Preventive Dentistry, Sundernagar, Himachal Pradesh, India ${ }^{4}$ PG Student, Department of Orthodontics, Himachal Institute of Dental Sciences,

Paonta Sahib, Himachal Pradesh, India

${ }^{5}$ PG Student, Department of Orthodontics, Genesis Institute of Dental Sciences and

Research, Ferozepur, Punjab, India

${ }^{6}$ Dental Surgeon, Ambala City, Haryana, India

*Corresponding Author: Lucky Jindal, Senior Lecturer, Department of Paedodontics and Preventive Dentistry, JCD Dental College, Sirsa, Haryana, India.
Received: May 21, 2020

Published: June 09, 2020

(C) All rights are reserved by Lucky Jindal., et al.

\section{Abstract}

Dentists are often faced with sectioning and soldering implant supported superstructures and long span tooth supported fixed partial dentures. These steps increase chair time, procedural cost and decrease clinical efficiency. One way to decrease the number of clinical steps is by improving the accuracy of working cast/die system. A cast die system captures the necessary information so that it can be transported to the laboratory.

Keywords: Die Materials; Dentists; Dentistry

\section{Introduction}

Since years, dentistry has been dealing with the replacement of missing teeth with the use of synthetic materials [1]. The advent of implant dentistry has redefined the need for accuracy of working cast models. The natural dentition allows for some movement due to the elasticity of periodontal ligament, even though this is sometimes insufficient to offset working cast inaccuracies. Because of Osseointegration, movement of abutments that involve implants is limited to extremely small dimensions. Hence, the importance of accurate reproduction of the prepared teeth/abutments and maintaining their relationship cannot be overemphasized. According to glossary of Prosthodontic terms 1999 [2].

A die has been defined as the positive reproduction of the form of a prepared tooth in any suitable material.

A cast is defined as a life size likeness of some desired form. It is formed within or is a material poured into a matrix or impression of the desired form.
Ideal requirements for a die/cast material [3]

1. Should reproduce the tissue details accurately i.e. both the hard and the soft tissues.

2. Should be dimensionally stable under normal conditions of use and storage.

3. Setting expansions, contractions and dimensional variations in response to changes in temperature should be minimum.

4. Should be strong and durable to withstand the subsequent manipulative procedures without abrasion or fracturing. So, abrasion resistance, shear strength, edge strength should be comparable to withstand the finishing and carving procedures as in indirect inlays. The dentist and dental technicians are faced with four variables that can affect the quality of working casts during its fabrication and use.

5. Accuracy of the impression procedure.

6. Accuracy of the cast/die system.

7. Inherent setting expansions of the dental stones used.

8. Precise repositioning of the removable die. 


\section{Selection criteria for cast-die systems [4]}

1. The material should allow a dimensionally accurate cast and should be strong and resistant to abrasion.

2. It should be easily sectionable and easy to trim with routinely available materials.

3. It should be compatible with the separating agent so that the wax pattern doesn't stick.

4. It should reproduce surface details accurately.

5. It should be available in a colour that contrasts with the wax used so that the preparations margins can be seen.

6. It should be easily wettable by the wax. In addition, it must be compatible with the impression material.

7. Finally, the type of restoration needs to be considered, because certain procedures (e.g. some all ceramic crowns) require the strength of metal or epoxy resin and cannot be fabricated on weaker stone dies.

\section{Classification of dies}

Dies can be classified as:

According to the material [5] used for fabrication of the die:

- $\quad$ Non metallic

- Gypsum dies

- $\quad$ Resin dies

- $\quad$ Silicophosphate dies

- $\quad$ Ceramic dies

- $\quad$ Flexible dies

- Metallic

- $\quad$ Electroplated dies

- Low fusing alloys

- Amalgam dies

- $\quad$ Metal sprayed dies.

\section{Gypsum dies [6]}

Dental gypsum is derived from natural gypsum rock (exists as a dihydrate). It is the most commonly and popularly used die material.

Dental gypsums are available in 5 forms (ADA type I to type V) namely impression plaster, plaster of paris, dental stone, high strength dental stone and high strength high expansion stone. The gypsum setting reaction is due to the hydration of calcium sulfate hemihydrate:

$\mathrm{CaSO}_{4} \frac{1}{2} \mathrm{H}_{2} \mathrm{O}+1 \frac{1}{2} \mathrm{H}_{2} \mathrm{O} \rightarrow \mathrm{CaSO}_{4}, \mathrm{H}_{2} \mathrm{O}$

The hemihydrate is manufactured by heating the dihydrate under controlled conditions to drive off some water of crystallization (a process called as calcination). The differences in various types of gypsums are attributed to calcination.

Surface detail reproduction is acceptable with type IV and type $\mathrm{V}$ gypsum products. These materials are capable of reproducing a $20 \mu \mathrm{m}$ wide line (ADA specification No.19).

Hand mixing of gypsum is easy, but results are better when the mixing is done mechanically in vacuum. Porosity is reduced with a concomitant increase in strength, after only 15 seconds of mechanical mixing. Ideally a 30 minutes of setting time is required for better results.

Gypsums greatest disadvantage is its relatively poor resistance to abrasion. Attempts to increase surface hardness and abrasion resistance have included the use of so called 'gypsum hardeners' (colloidal silica) improves the abrasion resistance. Another method is by impregnating the surface of the die with a low viscosity resin - cyanoacrylate or epoxy resins etc. A solution of $10 \%$ polystyrene in amyl acetate can be painted on the surface of die and then excess blown off. Incorporation of wetting agents such as lignosulphonates has also been employed.

Incorporation of gum arabic and calcium hydroxide to the gypsum showed an improvement in the hardness of type III stone through no such change in the hardness of type IV stone was observed in fact a decrease in strength was seen.

There are 2 basic working casts and die systems:

- Working cast with a separate die

- Working cast with a removable die.

Working cast with a separate die [7]

This is the simplest means of fabricating a working cast and die, since no other procedures are required other than making a sectional cast and a full arch cast.

\section{Armamentarium}

- 500 cc Vac-U-mixer and vacuum tubing

- Vibrator

- Water measure

- $\quad$ Large and small spatulas 
- Die stone

- Humidor

- Model trimmer

- Straight hand piece

- Lab knife

- Tanner carver

- Colorbrite red pencil.

Procedure

- Impression is poured using type IV (Densite) die stone or type $\mathrm{V}$ high strength high expansion die stone.

- The cast is then carefully separated from the impression. Wet the cast thoroughly before trimming excess stone from the working casts on model trimmer. Hold the cast by the base while cutting it down to form a handle on the die, handle of die should be slightly larger in diameter than the preparation and octagonal in cross section. Its sides ought to be parallel or slightly tapered towards the base, should be parallel to long axis of tooth and approximately 1.0 inch long (if it is any shorter, it will be difficult to hold when the wax pattern is on it).

- A pear shaped diamond bur is used to trim the die apical to finish line of the preparation approximating the contour of the root to facilitate good axial contours in the finished preparation.

- After the die has been trimmed the finish line should be highlighted with a sharp red pencil (this facilitates carving the margins of the wax patterns when wax observes the preparation finish line).

- $\quad$ Relief should be applied to preparation areas to provide space for cements. A die hardening agent like cynoacrylate or acrylic resin lacquer can be applied to finish line area of the die to prevent abrasion from carving instruments.

The multiple pour intact cast technique

This technique involves the use of a separate intact casts in addition to individual dies. It may be used with either 1 or 2 sets of dies if 2 sets are used; the dies from first pour are used for the final readaptation of wax pattern and as an emergency backup in case a second casting is needed after an unsatisfactory casting.

\section{Technique}

The die stone and liquid are mixed according to the manufacturer's instructions so that the stone has a consistency that allows it to flow readily and also stay in place when not disturbed. A small amount of properly mixed stone is picked up with a small stiff brush or a small metal instrument and placed on the inside edge of the impression of one of the tooth preparations and vibrated to the bottom of the preparation using a mechanical vibrator.

The stone may be introduced directly into the bottom of the impression if the preparation is big enough to allow this without entrapment of air bubbles.

The addition of small increments of stone is done until the impression of the preparation is filled with slight excess of material. The other prepared tooth are filled in a similar fashion when all impressions have been filled, an amount of mixed stone sufficient to form the root of the die is picked up and shaped with the fingers, the water content is reduced by blotting with paper towel, so as to allow the material to be placed on the stone already in the impression and to remain in place until it has set.

After about 30 minutes, the stone is set enough to allow easy removal of the dies. If a second set of dies are required the procedure can be repeated.

A working cast is obtained, the stone is mixed and poured into the impression, starting with the prepared teeth and then continuing to include all the teeth and the impression. Once the impression is filled, a base may be formed (about 10 - $15 \mathrm{~mm}$ thick).

\section{Advantages}

1. Ease of fabrication of wax patterns on separate dies.

2. The accuracy in development of proximal contacts.

3. The accuracy with which a fixed prosthesis can be assembled on an intact cast.

Disadvantages

a) The need to transfer a wax pattern between a die and a working cast particularly when there are inaccuracies in working cast and this can cause pattern fracture.

b) Technique suited for non-aqueous elastomeric impression materials where multiple pours can be obtained with sufficient accuracy for polysulphide and condensation polysilicon all pours should be over in 2 hours. Addition polysilicon has long term dimensional stability, the procedure may be carried out over a long period (days). This technique cannot be followed for hydrocolloid impressions. 


\section{Working cast with removable dies}

Dies that can be removed from the casts have become very popular. They are convenient to use because wax patterns or copings need not be removed from their respective dies when they are transferred to the casts.

A removable die should satisfy the following requirements:

a) The dies must return to their exact original positions.

b) The die must remain stable even when inverted.

c) The casts containing the die must be easy to mount on an articulator.

Several methods can be employed to reposition the die accurately in its working casts:

1. Most of these dies can be oriented in the impression before it is poured - Pre Pour Technique.

2. They can be attached to the cast that has already been poured - Post Pour Technique.

A tapered, flat-sided brass dowel pin can be used to orient the die of the prepared tooth into the working cast before pouring or after pouring. Flat-sided, stainless steel dowel pins with attached positioning wires also can be prepositioned. A different type of single dowel gains its stability from its curved shape. The dowel tip protrudes from the side rather than the bottom of the base of the cast.

Single dowels are simple to use, but they do not provide as much anti-rotational resistance as double dowels. Two separate dowels also can be cemented into parallel pinholes drilled in the underside of a cast, using a special drill press. Preformed plastic trays use multiple horizontal die-contact tracks and vertical ribs to orient dies back into the cast. They are especially useful for dies of teeth with dowel preparations that might be perforated by laboratory dowel pins protruding into the dowel space and for refractory dies onto which ceramic restorations will be fired.

Systems included are:

- Wet pinning system

- $\quad$ Straight dowel pin

- $\quad$ Curved dowel pin

- $\quad$ Dry pinning system

- $\quad$ Pindex system

- $\quad$ Dilok system

- DVA system

- Zeiser system

- Accutrac system.
Wet pinning system

a) Straight dowel pin [7,8]: This means of orienting dies has been in use for a number of years and most of the dowel systems are modifications of this. The brass dowel pin is one of the most accurate in terms of resisting horizontal displacement and the second lowest in vertical deviation among the mentioned die systems.

b) Curved dowel pin [7]: Curved dowels can be incorporated in a working cast by fixing the dowels to the impression before it is poured, or by cementing the dowels into holes drilled in a previously poured cast.

Dry pinning system: The precise placement of tapered die pins to allow the removal of individual dies presents a number of technical problems such as [3]:

a) Optimum location of the pins to the removable die.

b) Parallelism of die shafts.

c) Uniformity of length of die pins in relation to the base of the cast.

d) Smoothness of the die base at the interface with cast base material.

e) Guidance to prevent rotation and allow precise repositioning of die.

f) Stabilization of die pins during setting of the primary pour (during wet pinning technique).

Dry pinning approach allows the critical impression to be poured immediately thereby eliminating delay caused by adjustment apparatus for die pin orientation, which is necessary in a wet pinning procedure.

Pindex system [9]: The Pindex system was developed by Whaledent International. A similar system, developed by APM - Sterngold and named the Accudrill [10], is described as a dowel pin press. In the Pindex system, a reverse drill press is used to create a master cast with dies that can be removed and replaced repeatedly with great precision.

\section{Advantages of pindex system}

a) Only one impression pouring is required thus, it can be used with all types of impression materials including hydrocolloids whereas conventional methods are restricted to distortion free impression materials as it requires two pours. 
b) This system eliminates guess work as pins are accurately placed by mechanical instruments.

c) Rotation of dies is minimized by placing pins bucally and lingually. Thus, the dies are more stable despite repeated insertions and removals as they are housed in a plastic sleeve.

Dilok tray [7]

A snap apart plastic tray with internal orienting grooves and notches can also be used to resemble the working cast and die. This system has been found to have the least vertical error.

\section{DVA and Zeiser model system [3]}

The DVA Model System and the Zeiser model system use a precision drill and special baseplates that are aligned and drilled to provide die removal. These systems offer the advantage of allowing for the expansion of stone, which is relieved by the saw cuts.

\section{Accutrac [7]}

This removable die system is a modification of plastic tray with internal orientation grooves and notches (e.g. Accutrac, JF Jelenko, Armonk, NY).

\section{Resin dies [6,10,11]}

E.g. epoxy resin dies, polyurethane dies. Resin materials_have also been used for fabrication of dies for the preparation of inlays, crowns, fixed partial dentures using the indirect technique. These materials show good properties of strength, hardness, abrasion, resistance though with slight shrinkage occurring during polymerisation.

\section{Advantages}

1. Better strength and abrasion resistance than high strength stone dies.

2. Dimensionally stable and can be cured at room temperature.

3. Ideal material for reproducing details can reproduce groove depth up to $20 \mu \mathrm{m}$.

Disadvantages

Undergoes shrinkage during polymerisation which is approximately the same as expansion with stone dies. Hence, prosthesis fabricated on such dies are more tight fitting than those fabricated on stone dies. So, it may be necessary to make adjustments in casting and investment techniques accordingly.

1. Water retards polymerisation so resins cannot be used with water containing agar and alginate material, use is thus restricted to elastomer materials.

2. Resins are more viscous than stone so more prone to trap air bubbles so should be vibrated carefully.
3. Activator of epoxy resin is toxic and should not come in contact with skin during polymerisation or setting.

Other types of dies based on materials

Silicophosphate dies [12]: Similar to filling and cementing material.

- Advantage: Harder than die stone.

- Disadvantage: Shrinkage on setting, loss of water on standing. Ceramic die [12]: Two ceramic die materials are available:

- A material for the production of dies on which porcelain restorations are to be fabricated, without the use of a platinum foil matrix. To form the dies heating to over $1000^{\circ} \mathrm{C}$ is necessary.

- A ceramic material, supplied as powder and liquid, and mixed to a putty like consistency. After 1 hour material is removed from the impression and fired at $600^{\circ} \mathrm{C}$ for 8 minutes to produce a hard strong die.

Electroplated dies [10,13]: Dies formed by electroplating are used in the construction of ceramic and PFM restorations particularly for full mouth reconstruction as the chances for abrasion of dies are higher for the construction of appliances involving ceramics than for all metal ones. Plating solutions vary in their ability to plate concave surfaces, such as tooth surfaces of impressions. This plating ability is referred to as throwing power. Considering the size, depth, shape of impressions of teeth, solutions, with considerable throwing power are required for dental applications.

Copper plating: Metal dies can be made by copper plating compound or silicone impressions.

Problems in metal forming:

- Faulty conduction

- Exhausted solution

- Overconcentrated solution

- Metal anode too small

- Friable metal deposits.

Advantages of electroplating

- Better abrasion resistance than stone dies.

- Better reproduction of details.

Disadvantages:

- Time consuming process 12 - $15 \mathrm{hrs}$ for plating. 
- Silver cyanide solution used produces toxic fumes so contact with skin should be avoided and also such solutions have to be disposed off properly.

- Cannot be used with hydrocolloid impression materials.

Amalgam dies [12]: These dies are made in impressions made with impression compound in the copper band procedure.

\section{Advantages}

- $\quad$ Produces a hard die

- Adequate reproduction of fine details and sharp margins.

Disadvantages

- Can only be picked into a rigid impression

- Time consuming process

- High thermal conductivity can cool a wax pattern. This can be overcome by warming the die.

\section{Metal sprayed dies $[9,14]$}

A bismuth tin alloy, which melts at $138^{\circ} \mathrm{C}$ can be sprayed directly on to an impression to form a metal shell, which can then be filled with dental stone.

\section{Advantage}

A metal sprayed die can be obtained rapidly from elastomeric impression materials.

\section{Disadvantage}

The alloy is rather soft, care is needed to prevent abrasion of the die.

\section{Developments}

Combined die investment stone and die stone for making resin retained prosthesis [15]

The development of DVP (divestment phosphate) has made possible the development of a phosphate-bonded refractory cast and a framework pattern than can be invested and cast without removal from the DVP investment cast.

Advantage: More accurate castings.

Flexible die materials [16]: Flexible die materials are similar to heavy body silicones or polyether impression materials and have been used to make provisional restorations or indirect composite resin inlays or onlays chairside. A precaution to be kept in mind when choosing material for flexible dies, is to select a compatible combination of impression and die material that provides good surface details.

\section{Advantages}

- $\quad$ These flexible casts and dies enable easy fabrication and removal of interim restorations from the casts thus overcoming the problems of arches with undercuts.

- Biologically more compatible method because of its indirect nature.

- Faster procedure than that of gypsum dies because of flexibility of polyvinyl resin and more rapid setting of the materials used.

\section{Disadvantage}

- $\quad$ Expensive material.

\section{Summary and Conclusion}

The choice of a specific technique relies on operator preference and after assessment of each methods advantages and disadvantages. If they are conducted carefully all methods achieve clinically acceptable accuracy. No single die material or fabrication technique possess all the ideal properties, for an indirect working model, gypsum products have gained general acceptance and popularity because they more closely approximate the critical properties of an ideal die materials and an ideal die-cast system.

\section{Bibliography}

1. Jindal L., et al. "Stem cells - the tiny procreators: a review article". Asian Pacific Journal of Health Sciences 6.1 (2019): 118123.

2. "Glossary of Prosthodontic Terms". Journal of Prosthetic Dentistry 81.1 (1999): 39-110.

3. Resensteil SF., et al. "Contemporary fixed prosthodontics". $3^{\text {rd }}$ edition. Harcourt Mosby: 431-438.

4. Thornton LJ. "Simplified procedure for preparing removable dies”. Journal of Prosthetic Dentistry 85.3 (2001): 306-307.

5. Cohen J. "New Die Materials in Dentistry". 44.9 (1962): 441443.

6. Phillips RW. "Skinners Science of Dental Materials". 9 $^{\text {th }}$ edition (1992): 415-417.

7. Shillingburg HT. "Fundamentals of Fixed Prosthodontics $3^{\text {rd }}$ edition”. Quintessence Publishing Co. Inc (1997): 309. 
8. Sweeney WT and Taylor DF. "Dimensional Changes in Dental Stone and Plaster". Journal of Dental Research 29.6 (1950): 749.

9. Wiskott A. "Laboratory procedures and clinical implications in the making of casts". Quintessence International 18.3 (1987): 181-192.

10. Craig RG and Powers JM. "Restorative Dental Materials". $11^{\text {th }}$ edition: 168-173.

11. O' Brien WJ. "Dental materials and their selection". $2^{\text {nd }}$ edition: 337-341.

12. Combe EC. "Notes on dental materials". $6^{\text {th }}$ edition: 65-66.

13. Fusayama T. "Dimensional Form and Hardness Changes of Dies for Indirect Dental Technic". Journal of the American Dental Association 52.2 (1956): 270-271.

14. Ayers HD. "Detail Duplication Test for Dental Materials". New York State Dental Journal 25 (1959): 82.

15. Kanoy BE and Strayhorn LW. "Combined die investment stone and die-stone cast for making resin retained prosthesis". Journal of Prosthetic Dentistry 53.2 (1985): 285-287.

16. Roberts DB. "Flexible casts in making indirect interim restorations". Journal of Prosthetic Dentistry 68.2 (1982): 372-374.

\section{Assets from publication with us}

- Prompt Acknowledgement after receiving the article

- Thorough Double blinded peer review

- Rapid Publication

- Issue of Publication Certificate

- High visibility of your Published work

Website: www.actascientific.com/

Submit Article: www.actascientific.com/submission.php

Email us: editor@actascientific.com

Contact us: +919182824667 